\title{
From theory to the bedside of the patient: it's a long and devious way to go
}

\author{
L. Noyez
}

Published online: 13 August 2013

(C) The Author(s) 2013. This article is published with open access at Springerlink.com

Perioperative adverse cardiovascular events (PACE), although infrequent, are responsible for about $60 \%$ of mortality after non-cardiac surgery [1].

Most PACE-related deaths are related to cardiovascular complications as myocardial ischaemia, infarction, rhythm disturbances and stroke $[2,3]$. Despite technical improvements and increased monitoring in recent years, the rates of PACE remain stable. Several articles deal with identification of risk factors for PACE and several risk stratification models have been presented $[4,5]$.

As Grobben et al. [6] state, recognition of PACE is difficult, certainly because these events are often masked by the use of analgesics. Moreover, the classic cardiac biomarkers as cardiac troponin are not reliable since operation and postoperative related factors also interfere with the normal serum levels of these classic markers [7]. This 'recognition problem' of course results in difficulty in identifying variables that might indicate risk and in building a risk stratification model. On that point Grobben et al. are right that to ensure early recognition of PACE, knowledge of its aetiology needs to be improved [6]. In their review article, they focus on four pathophysiological mechanisms: myocardial infarction type I, myocardial infarction type II, non-ischaemic cardiac pathology and non-cardiac causes. In the discussion the authors argue this distinction based on the literature. What the authors, however, do not discuss in their paper is how this pathophysiological distinction can result in better recognition of PACE events, a condition sine

\section{Noyez $(\bowtie)$}

Heart Center, Department of Cardio- Thoracic Surgery - 677, Radboud University Nijmegen Medical Center, PO Box 9101, 6500 HB Nijmegen, the Netherlands

e-mail:1.noyez@ctc.umcn.nl qua non to identify perioperative variables that might indicate risk and to build and validate risk prediction models.

We may hope that their review will be a first step and will have a more practical continuation resulting in better identification of PACE leading to identification of simple, objective and easily recorded variables associated with PACE and so better patient care.

Funding None.

Conflict of interests None declared.

Open Access This article is distributed under the terms of the Creative Commons Attribution License which permits any use, distribution, and reproduction in any medium, provided the original author(s) and the source are credited.

\section{References}

1. Pearse RM, Moreno RP, Bauer P, et al. Mortality after surgery in Europe: a 7 day cohort study. Lancet. 2012;380:1059-65.

2. Devereaux PJ, Goldman L, Cook DJ, et al. Perioperative cardiac events in patients undergoing noncardiac surgery: a review of the magnitude of the problem, the pathophysiology of the events and methods to estimate communicate risk. CMAJ. 2005;173:627-34.

3. Fleisher LA, Lehman HP. Preoperative cardiac evaluation and perioperative monitoring for noncardiac vascular surgery. JAMA. 1995;274:1671-2.

4. Boersma E, Kertai MD, Schouten O, et al. Perioperative cardiovascular mortality in noncardiac surgery: validation of the Lee cardiac risk index. Am J Med. 2005;118:1134-41.

5. Sabate S, Mases A, Guilera N, et al. Incidence and predictors of major perioperative adverse cardiac and cerebrovascular events in noncardiac surgery. BJA. 2011;107:879-90.

6. Grobben R, Van Klei W, Grobbee D, et al. The aetiology of myocardial injury after non-cardiac surgery. Neth Heart J. 2013. doi:10.1007/s12471-013-0463-2.

7. Wong P, Murray S, Robinson A, et al. Raised cardiac troponin T levels in patients without acute coronary syndrome. Postgrad Med J. 2007;83:200-5. 